\title{
Factors for peripherally inserted central catheters care delay in cancer patients during the COVID-19 pandemic
}

\author{
Liyang Hu ${ }^{1 \#}$, Hongmei Tao ${ }^{2 \#}$, Xiaolu Xu ${ }^{1 \#}$, Hui Chen ${ }^{3}$, Kejie Chang ${ }^{1}$, Xiaofeng Pei ${ }^{1}$, Fen Hao ${ }^{1}$, \\ Lanman $\mathrm{He}^{1}$, Yanni Chen ${ }^{4}$, Zibin Liang ${ }^{1}$, Tongtong Luo ${ }^{1}$, Zhong Lin ${ }^{1}$, Weize Lv $^{5}$, Fengjiao Long ${ }^{1}$ \\ ${ }^{1}$ Department of Thoracic Oncology, ${ }^{2}$ Department of Nursing, ${ }^{3}$ Department of Abdominal Oncology, ${ }^{4}$ Department of Peripherally Inserted Central \\ Catheters Outpatient Service, ${ }^{5}$ Department of Tumor Intervention Treatment, the Cancer Center of the Fifth Affiliated Hospital of Sun Yat-sen \\ University, Zhuhai, China \\ Contributions: (I) Conception and design: L Hu, H Tao, X Xu; (II) Administrative support: Z Lin, F Long; (III) Provision of study materials or \\ patients: Z Liang, T Luo, W Lv; (IV) Collection and assembly of data: F Hao, L He, Y Chen, T Luo; (V) Data analysis and interpretation: H Chen, \\ K Chang, X Pei; (VI) Manuscript writing: All authors; (VII) Final approval of manuscript: All authors. \\ \#These authors contributed equally to this work. \\ Correspondence to: Fengjiao Long. Department of Thoracic Oncology, the Cancer Center of the Fifth Affiliated Hospital of Sun Yat-sen University, \\ 52 Mei Hua Rd. East, Zhuhai 519000, China. Email: longfj@mail.sysu.edu.cn; Weize Lv. Department of Tumor Intervention Treatment, the Cancer \\ Center of the Fifth Affiliated Hospital of Sun Yat-sen University, 52 Mei Hua Rd. East, Zhuhai 519000, China. Email: lvweize@mail.sysu.edu.cn.
}

Background Coronavirus disease 2019 (COVID-19) has rapidly evolved into a global pandemic. The public health systems have consequently been placed under tremendous pressure. Peripherally inserted central catheters (PICCs) are widely used in patients with cancers. Little is known about the provision of PICCs care amongst cancer patients during this pandemic.

Methods: We studied 156 cancer patients with PICCs treated at the Cancer Center of the Fifth Affiliated Hospital of Sun Yat-sen University between January 2020 and March 2020. Their clinical characteristics, social features, psychological characteristics, and PICCs care situations were analyzed. The chi-squared $\left(\chi^{2}\right)$ test or Fisher's exact test were used for univariate analyses. Multivariate logistic regression analyses were performed using stepwise variable selection. Differences were evaluated using a two-tailed test, and $\mathrm{P}<0.05$ was considered statistically significant.

Results: Of 156 patients, 57 (36.5\%) experienced delays of PICCs care, and 12 (21.1\%) suffered from complications including infection, thrombosis, and mechanical failure. Univariate analysis detected that the increased risk of PICCs care delay was associated with older age $(\geq 30)$, lower level of education $(<9$ years), working, taking public transport to the hospital, anxiety about COVID-19, lower social support rating scale (SSRS) score (<30). Multivariate analysis detected level of education, being employed or not, mode of transport, and SSRS score were independent predictive factors for the delay in PICCs care.

Conclusions: Physical aspects, social factors, and psychological status commonly influenced patients' health care seeking behaviors such as PICCs maintenance. An increase in effort is required from patients' families and society to assure optimal care for cancer patients during this pandemic.

Keywords: Coronavirus disease 2019 (COVID-19); peripherally inserted central catheters care (PICCs care); risk factors; delay

Submitted Aug 10, 2020. Accepted for publication Nov 10, 2020.

doi: 10.21037/apm-20-1887

View this article at: http://dx.doi.org/10.21037/apm-20-1887 


\section{Introduction}

Coronavirus disease 2019 (COVID-19), which was highly infectious for human, has rapidly evolved into a global pandemic (1-3). By the end of May, there were $>5$ million reported cases of the virus, and more than 360 thousand deaths worldwide, according to the official website of the World Health Organization. The disease is highly transmissible through droplets, contaminated surfaces, and aerosols (4). With typical symptoms including fever, tiredness, and dry cough, the virus has widely spread in the space of several months (5). To date, more than 200 countries, territories, and areas have successively reported positive cases (6). The public health systems of many countries have been exposed to enormous pressure due to this severe global health emergency (7-10). Maintaining social distance is believed to be one of the key lines of defense in protecting susceptible populations. As a result, increasing numbers of people have remained isolated in their homes, aiming to reduce exposure to the populace (11). Moreover, increasing numbers of nosocomial infection have caused people to resist going to the hospital for fear of transmission $(12,13)$.

Due to the systemic immunosuppressive state caused by malignancies and anticancer treatments, patients with cancer are more susceptible to COVID-19 (13-15). Initial report suggested among patients with cancer and COVID-19, 30-day all-cause mortality was high and associated with general and cancer specific risk factors, with a mortality of $13.3 \%$ (16). Additionally, through visits for anticancer therapy, monitoring and supportive care, they often contact with the health-care system, putting them at increased risk for infection. During the pandemic, the Fifth Affiliated Hospital of Sun Yat-sen University hospital was selected as one of the officially designated institutions for COVID-19, some wards and staffs of our cancer center was requisitioned for COVID-19 treatment. Cancer patients subsequently faced the risk of being unable to receive necessary medical services due to a shortage of medical workers, or hesitations about visiting the hospital $(17,18)$.

Peripherally inserted central catheters (PICCs) are widely used to provide long-term intravascular access for chemotherapy, parenteral nutrition, and pain control in patients with cancer (19-21). For cancer patients, PICCs may help eliminate potentially life-threatening complications such as hemothorax and reduces the likelihood of arterial puncture and hemorrhage, with an alternative to subclavian or jugular vein catheterization (22).
Regular device checks and insertion-site care should be performed weekly to avoid infection and thrombogenesis $(23,24)$. However, regular visits to hospital for cancer patients with PICCs were greatly affected by the COVID-19 pandemic. To our knowledge, the conditions of PICCs care of Chinese patients with cancer during this pandemic have not yet been reported on. This study was conducted to evaluate the factors affecting patient visits to the hospital for PICCs care, and to seek solutions to the issues prohibitive to satisfactory PICCs care during this period. We present the following article in accordance with the STROBE reporting checklist (available at http://dx.doi. org/10.21037/apm-20-1887).

\section{Methods}

\section{Patient selection}

Patients treated at the Cancer Center of the Fifth Affiliated Hospital of Sun Yat-sen University from January 2020 to March 2020 were included in this study. All participants had had malignant tumor diagnosed by biopsy and inserted PICCs for treatment previously. They were instructed to receive PICCs care at the hospital weekly following insertion. Patients eligible for inclusion were aged 16 years or older, with a diagnosed solid or lymphohematopoietic malignancy at any stage and with peripherally inserted central catheters as vascular access. Patients with previous complications associated with PICCs including infection or thrombosis were excluded from this analysis.

The PICCs were placed while the patient was in a supine position. A proper vein (the basilic vein typically) was selected by ultrasound. Skin preparation was performed with chlorhexidine iodine to ensure the procedure was conducted sterilely. Venous puncture was performed with a 21 -gauge micropuncture needle under ultrasound guidance by skilled nurses.

Participants' clinical characteristics including gender, age, Eastern Cooperative Oncology Group (ECOG) score, pathological diagnosis, and stage of tumor were collected from our medical record system. Social details such as level of education, occupation, marital status, financial situation, living conditions, and religion were surveyed by questionnaire prior to the PICCs insertion. Social support rating scale (SSRS) was performed at the same time.

To investigate the psychological characteristics of participants, the Generalized Anxiety Disorder-7 (GAD-7) assessment, and the Patient Health Questionnaire-9 (PHQ-9) 


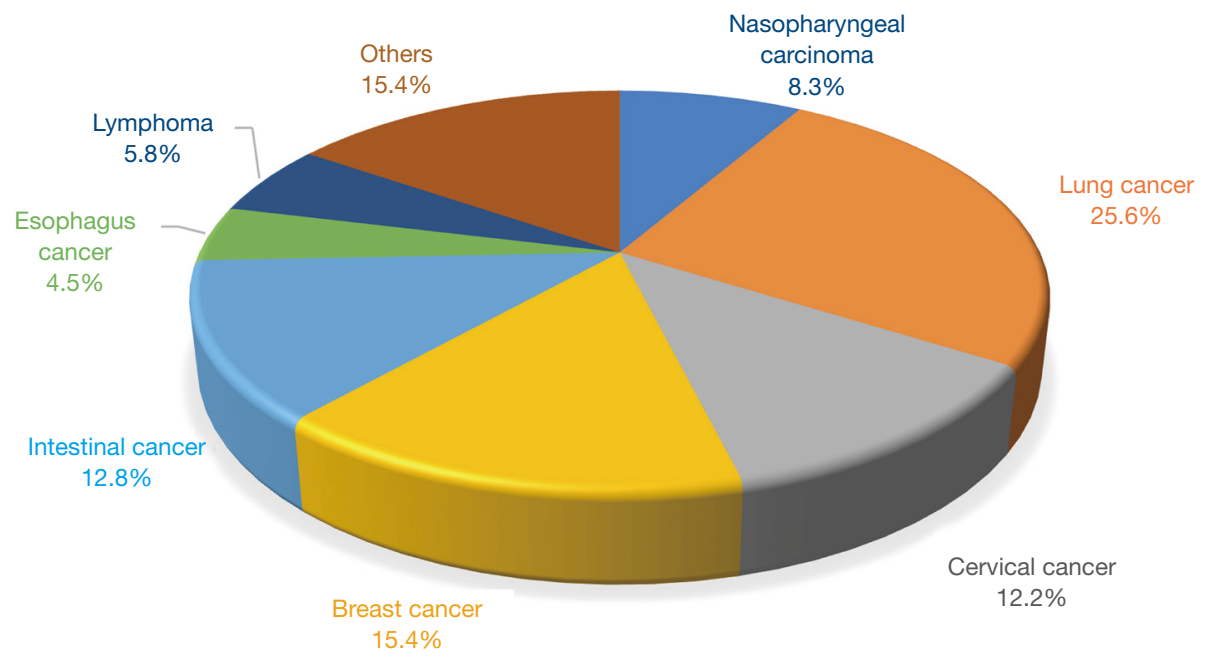

Figure 1 Constituents of 156 cancer patients.

were conducted in this study. Anxious and depressive symptoms were assessed via these scales respectively, which were self-reported questionnaires including several items. Our study was approved by the Institutional Review Board of the Fifth Affiliated Hospital of Sun Yat-sen University (Approval No. ChiCTR2000029830). The study was conducted in accordance with the Declaration of Helsinki (as revised in 2013). All participants were fully informed and gave consent before taking questionnaires.

\section{Follow-up}

All patients were required to return to the hospital for PICCs care weekly following insertion. The time of return visit, mode of transport, and attitude about visiting the hospital (concerned or not) were recorded. A delay was considered if the time of return visit was $\geq 3$ days later than the scheduled time. The final follow-up date in this study was 31 May 2020.

\section{Statistical analysis}

To study the factors affecting regular PICCs care, the chisquared $\left(\chi^{2}\right)$ or Fisher's exact test were used for univariate analyses. All factors with $\mathrm{P}$ values $<0.10$ were included in the multivariate analysis. Multivariate logistic regression analyses were performed using stepwise variable selection to explore independent influences. Differences were evaluated using a two-tailed test, and $\mathrm{P}<0.05$ was considered statistically significant. All statistical analyses were carried out using SPSS version 19.0 (IBM, Armonk, NY, USA).

\section{Results}

A total of 156 patients in the Cancer Center of the Fifth Affiliated Hospital of Sun Yat-sen University were included in this study. There were $13(8.3 \%)$ nasopharyngeal carcinoma cases, 40 (25.6\%) lung cancer cases, $19(12.2 \%)$ cervical cancer cases, 24 (15.4\%) breast cancer cases, 20 (12.8\%) intestinal cancer cases, 7 (4.5\%) esophagus cancer cases, 9 (5.8\%) lymphoma cases, and $24(15.4 \%)$ cases of other malignant tumors (the detailed constituents of cancers are displayed in Figure 1). Among these patients, 81 (51.9\%) were men, and 75 (48.1\%) were women. The median age of all participants was 55 years (16-88 years), and 7 (4.5\%) patients were $<30$ years old. There were 127 cases $(81.4 \%)$ with advanced-stage disease (stages III and IV); ECOG $<3$ scores were found in 139 (84.1\%) patients; 105 (67.3\%) cases had an education level $<9$ years. There were $128(82.1 \%)$ recipients of antitumor treatment, and the remaining 28 (17.9\%) participants received supportive treatment without antineoplastic drugs. At a median follow-up of 31 days (12-45 days), $57(36.5 \%)$ patients experienced a delay in PICCs care. Of these patients, $12(21.1 \%)$ suffered from complications such as infections, thrombosis, and mechanical failure (detailed characteristics of patients are shown in Table 1).

\section{Univariate and multivariate analysis}

Univariate analysis detected that the increased risk of PICCs care delay was associated with older age $(\geq 30)$, lower level of education ( $<9$ years), work-related commitments, 
Table 1 Characteristics of the 156 cancer patients with peripherally inserted central catheters (PICCs) and univariate analysis for risk factors of PICCs care delay

\begin{tabular}{|c|c|c|c|c|}
\hline Characteristics & Total $(n=156)(\%)$ & \multicolumn{2}{|c|}{ PICCs care delay } & $P$ \\
\hline Gender & & & & 0.39 \\
\hline Male & $81(51.9)$ & $27(47.4)$ & $54(54.5)$ & \\
\hline Female & $75(48.1)$ & $30(52.6)$ & $45(45.5)$ & \\
\hline$\geq 30$ & $149(95.5)$ & $57(100)$ & $92(92.9)$ & \\
\hline$<30$ & $7(4.5)$ & $0(0)$ & $7(7.1)$ & \\
\hline Education & & & & $<0.01$ \\
\hline$\geq 9$ years & $51(32.7)$ & $7(12.3)$ & $44(44.4)$ & \\
\hline$\geq 3$ & $17(10.9)$ & $4(7)$ & $13(13.1)$ & \\
\hline$<3$ & $139(89.1)$ & $53(93)$ & $86(86.9)$ & \\
\hline Tumor stage & & & & 0.86 \\
\hline $1-2$ & $29(18.6)$ & $11(19.3)$ & $18(18.2)$ & \\
\hline $3-4$ & $127(81.4)$ & $46(80.7)$ & $81(81.8)$ & \\
\hline Anti-tumor treatment & & & & 0.23 \\
\hline Yes & $128(82.1)$ & $44(77.2)$ & $84(84.8)$ & \\
\hline No & $28(17.9)$ & $13(22.8)$ & $15(15.2)$ & \\
\hline Married & $143(91.7)$ & $54(94.7)$ & $89(89.9)$ & \\
\hline Economic pressures & & & & 0.21 \\
\hline Yes & $126(80.8)$ & $49(86)$ & $77(77.8)$ & \\
\hline No & $30(19.2)$ & $8(14)$ & $22(22.2)$ & \\
\hline Living areas & & & & 0.49 \\
\hline Urban & $85(54.5)$ & $29(50.9)$ & $56(56.6)$ & \\
\hline Rural & $71(45.5)$ & $28(49.1)$ & $43(43.4)$ & \\
\hline Having children & & & & 0.1 \\
\hline Yes & 147 (94.2) & $56(98.2)$ & 91 (91.9) & \\
\hline No & $9(5.8)$ & $1(1.8)$ & $8(8.1)$ & \\
\hline
\end{tabular}

Table 1 (continued) 
Table 1 (continued)

\begin{tabular}{|c|c|c|c|c|}
\hline Characteristics & Total $(n=156)(\%)$ & \multicolumn{2}{|c|}{ PICCs care delay } & $\mathrm{P}$ \\
\hline Having brother or sister & & & & 0.65 \\
\hline Yes & $149(95.5)$ & $55(96.5)$ & $94(94.9)$ & \\
\hline No & $7(4.5)$ & $2(3.5)$ & $5(5.1)$ & \\
\hline Yes & $17(10.9)$ & $3(5.3)$ & $14(14.1)$ & \\
\hline No & $139(89.1)$ & $54(94.7)$ & $85(85.9)$ & \\
\hline Living with families & & & & 0.49 \\
\hline Yes & $150(96.2)$ & $54(94.7)$ & $96(97.0)$ & \\
\hline Yes & $61(39.1)$ & $24(42.1)$ & $37(37.4)$ & \\
\hline No & $95(60.9)$ & $33(57.9)$ & $62(62.6)$ & \\
\hline Ample sleep & & & & 0.66 \\
\hline Yes & $54(34.6)$ & $21(36.8)$ & $33(33.3)$ & \\
\hline No & $102(65.4)$ & $36(63.2)$ & $66(66.7)$ & \\
\hline Taking public transport to hospital & & & & $<0.01$ \\
\hline Yes & $72(46.2)$ & $36(63.2)$ & $36(36.4)$ & \\
\hline No & $84(53.8)$ & $21(36.8)$ & $63(63.6)$ & \\
\hline Yes & $3(1.9)$ & $2(3.5)$ & $1(1.0)$ & \\
\hline No & $153(98.1)$ & $55(96.5)$ & 98 (99.0) & \\
\hline Worried about going hospital & & & & 0.01 \\
\hline Yes & $44(28.2)$ & $23(40.4)$ & $21(21.2)$ & \\
\hline No & $112(71.8)$ & $34(59.6)$ & $78(78.8)$ & \\
\hline Time with PICCs & & & & 0.16 \\
\hline$\geq 3$ months & $87(55.8)$ & $36(63.2)$ & $51(51.5)$ & \\
\hline$<3$ months & $69(44.2)$ & $21(36.8)$ & $48(48.5)$ & \\
\hline SSRS score & & & & $<0.01$ \\
\hline$\geq 30$ & $119(76.3)$ & $34(59.6)$ & $85(85.9)$ & \\
\hline$<30$ & $37(23.7)$ & $23(40.4)$ & $14(14.1)$ & \\
\hline
\end{tabular}

Table 1 (continued) 
Table 1 (continued)

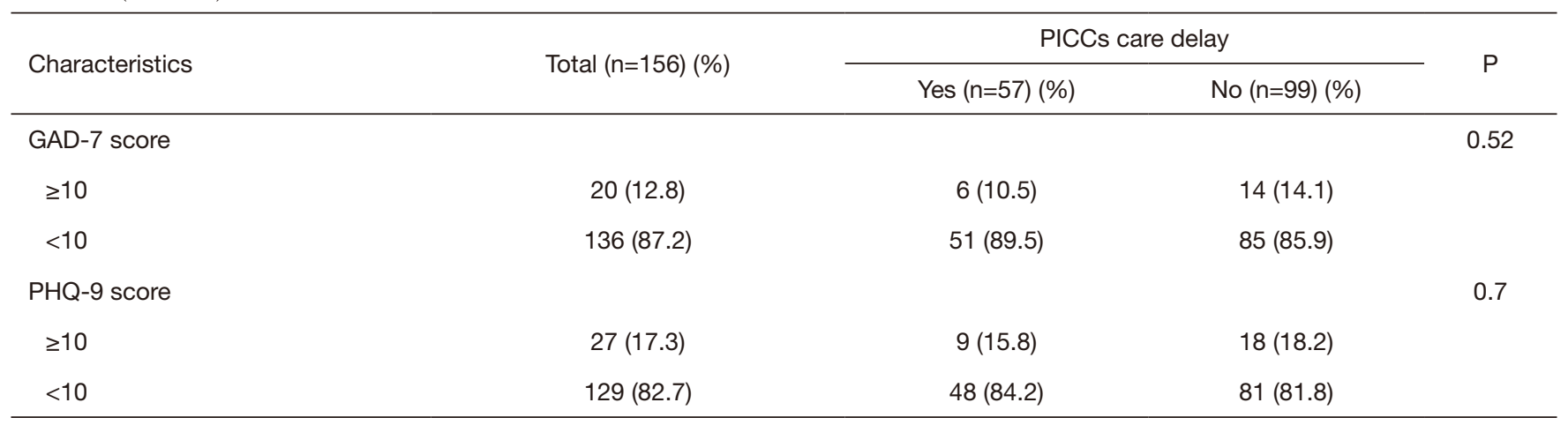

${ }^{a}$, the living community of patients were under lockdown for prevention of COVID-19 spread; ${ }^{b}$, some acquaintances of patients were under medical observation for suspicion of COVID-19 infection. ECOG, Eastern Cooperative Oncology Group; SSRS, social support rate scale; GAD-7, Generalized Anxiety Disorder-7; PHQ-9, Patient Health Questionnaire-9.

Table 2 Multivariate analysis for risk factors of peripherally inserted central catheters (PICCs) care delay

\begin{tabular}{llcl}
\hline Characteristics & HR & $95 \% \mathrm{Cl}$ & $\mathrm{P}$ \\
\hline Highly educated $^{\mathrm{a}}$ & 0.16 & $0.06-0.42$ & $<.01$ \\
On job & 8.26 & $1.67-40.88$ & 0.01 \\
Taking public transport & 3.57 & $1.62-7.87$ & 0.02 \\
High SSRS score $^{b}$ & 0.29 & $0.12-0.72$ & 0.01 \\
\hline
\end{tabular}

${ }^{\mathrm{a}}$, the patients with education experience more than 9 years; ${ }^{\mathrm{b}}$, the patients with social support rate scale score more than 30. SSRS, social support rate scale.

taking public transport to the hospital, anxiety related to COVID-19, and lower SSRS score $(<30)$ (detailed data is displayed in Table 1).

In the multivariate analysis, level of education, employment status, mode of transport, and SSRS score were independent predictive factors for delayed PICCs care (details shown in Table 2).

\section{Social psychological analysis}

While investigating the participants' social support, we found that patients who underwent anti-tumor treatment and patients with financial pressures tended to have higher SSRS scores in univariate analysis. In the review of patients' mental health, we found living with family decreased the risk of depressive symptoms (detailed data is displayed in Table 3).

\section{Advices from patients}

To improve PICCs care, and decrease the probability of delays in care, the survey revealed that 35 (22.4\%) patients had hoped that nurses would provide an out of hospital service, enabling them to receive PICCs care at home; 45 $(28.8 \%)$ participants would have liked more information about PICCs, to better understand the importance of PICCs care; 66 (42.3\%) patients suggested the hospital should sterilize wards and medical instruments thoroughly, and set up an isolation area for COVID-19 patients to protect other patients from infection (data is shown in Figure 2).

\section{Discussion}

Outbreaks of COVID-19 have caused significant global mortality and morbidity, and mental health has been widely impacted $(2,7,9,25,26)$. Since the onset of this pandemic, PTSD has been affecting $4-41 \%$ of citizens, and there has been a rise in the prevalence of major depression by $7 \%$ (27). It showed that prevalence in the general population of PTSD had been ranging from $4 \%$ to $41 \%$ and the prevalence of major depression increased by $7 \%$ after the outbreak 
Table 3 Univariate analysis for risk factors of social support, anxiety and depression

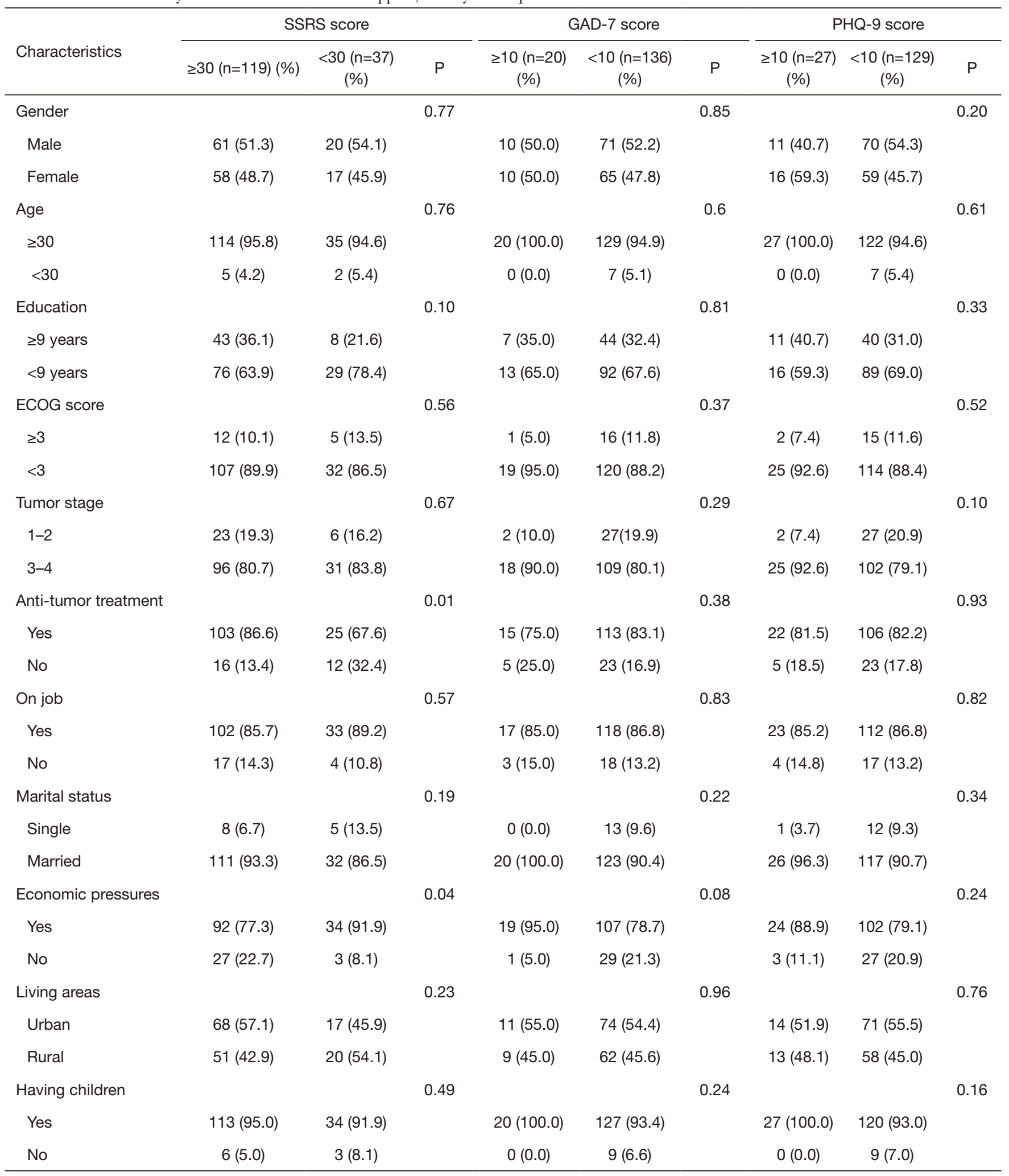

Table 3 (continued) 
Table 3 (continued)

\begin{tabular}{|c|c|c|c|c|c|c|c|c|c|}
\hline Characteristics & \multicolumn{3}{|c|}{ SSRS score } & \multicolumn{3}{|c|}{ GAD-7 score } & \multicolumn{3}{|c|}{ PHQ-9 score } \\
\hline Yes & $115(96.6)$ & $34(91.9)$ & & $19(95.0)$ & $130(95.6)$ & & $26(96.3)$ & $123(95.3)$ & \\
\hline Be religious & & & 0.22 & & & 0.16 & & & 0.16 \\
\hline Yes & 15 (12.6) & $2(5.4)$ & & $4(20.0)$ & $13(9.6)$ & & $5(18.5)$ & $12(9.3)$ & \\
\hline No & $104(87.4)$ & $35(94.6)$ & & $16(80.0)$ & $123(90.4)$ & & $22(81.5)$ & $117(90.7)$ & \\
\hline Living with families & & & 0.12 & & & 0.77 & & & 0.03 \\
\hline $\begin{array}{l}\text { Taking public transport } \\
\text { to hospital }\end{array}$ & & & 0.14 & & & 0.55 & & & 0.85 \\
\hline Yes & $51(42.9)$ & $21(56.8)$ & & $8(40.0)$ & $64(47.1)$ & & $12(44.4)$ & $60(46.5)$ & \\
\hline No & $68(57.1)$ & $16(43.2)$ & & $12(60.0)$ & $72(52.9)$ & & $15(55.6)$ & $69(53.5)$ & \\
\hline Community lockdown ${ }^{a}$ & & & 0.98 & & & 0.35 & & & 0.18 \\
\hline Yes & $71(59.7)$ & $22(59.5)$ & & $10(50.0)$ & $83(61.0)$ & & $13(48.1)$ & $80(62.0)$ & \\
\hline No & $48(40.3)$ & $15(40.5)$ & & $10(50.0)$ & $53(39.0)$ & & $14(51.9)$ & $49(38.0)$ & \\
\hline Having acquaintances & & & 0.69 & & & 0.5 & & & 0.42 \\
\hline$\geq 3$ months & $67(56.3)$ & $20(54.1)$ & & $8(40.0)$ & $79(58.1)$ & & $12(44.4)$ & $75(58.1)$ & \\
\hline$<3$ months & $52(43.7)$ & $17(45.9)$ & & $12(60.0)$ & 57 (41.9) & & 15 (55.6) & $54(41.9)$ & \\
\hline
\end{tabular}

${ }^{a}$, the living community of patients were under lockdown for prevention of COVID-19 spread; ${ }^{\text {, }}$, some acquaintances of patients were under medical observation for suspicion of COVID-19 infection. SSRS, social support rate scale; GAD-7, Generalized Anxiety Disorder-7; PHQ-9, Patient Health Questionnaire-9.

Torales et al. reviewed published articles concerning mental health related to the COVID-19 outbreak and other previous global infections, and reported that this outbreak was leading to increased global mental health issues including insomnia, anger, depressive symptoms, stress, anxiety, denial, and fear. In a compounding of problems, collective concerns have influenced daily behaviors, the economy, prevention strategies and decision-making from policy makers, health organizations and medical centers; these hindrances can weaken strategies of COVID-19 control, and increased morbidity and mental health crises at the global level may ensue (27).

COVID-19 pandemic brings extra risks for cancer patients. In the study of the outcomes in a cohort of patients with cancer and COVID-19 by Kuderer and colleagues, they collected data on patients with active or 


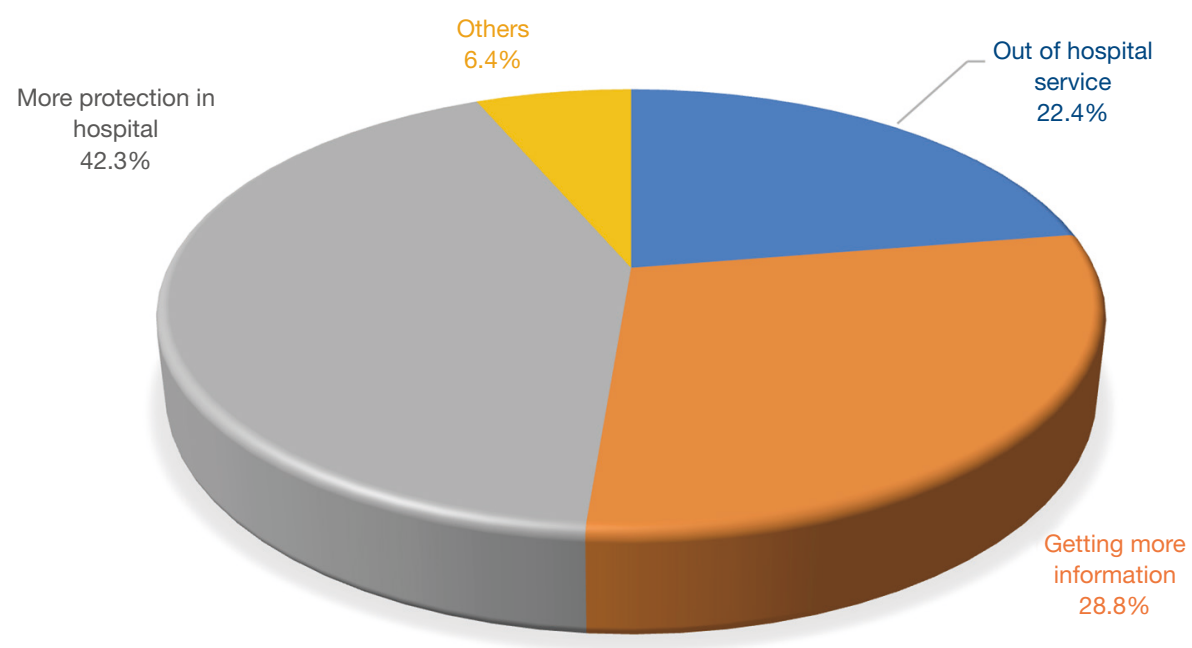

Figure 2 Suggestions of 156 cancer patients to improve peripherally inserted central catheters care.

previous malignancy with confirmed COVID-19 infection. Analysis of 928 patients showed independent factors for increased 30-day mortality included increased age, male sex, smoking status, active cancer, smoking status, number of comorbidities and so on.

Although related studies are scarce, it is clear that patients' health seeking behaviors during this pandemic have significantly changed (28). Ali et al. studied migraine sufferers who frequently attended face-to-face visits for infusion treatments and interventions, and reported on 3 cases, concluding that innovative strategies were needed to enable satisfactory ongoing care of migraine patients throughout the era of COVID-19 (29). To highlight the importance of prompt brachytherapy for patients with breast, gynecological, and prostate malignancies during the COVID-19 pandemic, Williams et al. reviewed accumulating evidence to facilitate the path towards management and scheduling of brachytherapy, and found that reducing patient exposure and the use of resources was important during COVID-19, they then stated that all measures should be taken to guarantee the prompt delivery of brachytherapy for patients (30). Wallis et al. reviewed the risks of deferring treatment for genitourinary cancers during the COVID-19 pandemic, and found that for patients with high-grade upper tract urothelial cancer, delays of 12 weeks for nephroureterectomy were not associated with adverse survival outcomes; for penile cancer, adverse outcomes had been observed with delays $\geq 3$ months preceding inguinal lymphadenectomy. They considered that it was important to adequately triage the care of patients for whom the probability of adverse outcomes would most likely result from delays, with consideration for the patient's symptoms, age, comorbidities, and prognosis for survival time (31).

For patients with malignant tumors, PICCs are important vascular access devices that facilitate prolonged intravenous therapies $(32,33)$. There are some complications associated with PICCs including infection or thrombosis, and appropriate care may reduce the risk of such harms $(32,34,35)$. In the study of Piorkowska et al. about PICCs care, it was mentioned that factors contributing to the significant rate of blockage included lengthy and confusing PICCs care guidelines, an absence of information sheets in patient notes, inadequate training for and appreciation of maintenance and flushing of PICCs lines, and a lack of liability regarding PICCs flushing (24). Duwadi et al. reported that early detection of complications, and customized care of PICCs were significant factors for preventing complications. Establishing appropriate education, training, and multidisciplinary approaches for PICCs care among nurses and caregivers were identified as keys to preventing the incidence of complications (21). In our study, 57 (36.5\%) patients experienced delays in PICCs care and 12 of the $57(21.1 \%)$ endured complications associated with delayed treatment. This revealed the need to minimize delays in patient care and improve patient compliance through appropriate adaptive interventions (36).

Song et al. examined 549 hospitalized patients aged 66-104 years who were undergoing PICCs placement, and found a history of thrombosis, large number of lumens, and wide-gauge catheters were strong risk factors for patients 
aged $>65$ years undergoing PICCs placement (37). To estimate the incidence of and identify the risk factors for complications associated with PICCs, Badheka et al. (38). studied 2,558 hospitalized children, and suggested that younger children $(<5$ years old) were at an increased risk of developing PICCs related central line-associated bloodstream infection. To our knowledge, there is yet to be a report associated with the risk factors for PICCs care delay. Our study explored the main contributing factors of PICCs care delay, and several associated findings emerged. A general lack of information among the elderly and the less educated incites panic and anxiety among the populace (39). Deficiency of social support may foster loneliness and anger; a considerable number of our patients admitted being afraid of going out. These negative motions may interfere with their health seeking behaviors including the pursuit of PICCs care back at the hospital (40). As for the patients who are employed, a scarcity of time might account for their delay. Patients without private modes of transport objectively had a much higher probability of infection; therefore avoiding excursions during the pandemic might be more appealing for these patients (41). Moreover, physical aspects, social factors, and psychological status commonly influenced PICCs care, which was an important health seeking behavior of cancer patients.

To prevent the spread of COVID-19 among cancer patients and cancer care providers, Shankar et al. advised that oncologists be more vigilant in detecting coronavirus infection early, as any type of advanced cancer patient was at much higher risk for unfavorable outcomes; oncology communities should ensure that cancer patients predominantly isolate at home and minimize time mingling in the community; oncologists and other health care professionals involved in cancer care should hone patient communication in order to transmit reliable information regarding practice modifications due to COVID-19 outbreaks; countries should isolate, test, treat, and trace to attain control of the coronavirus pandemic (8). To control infection during this pandemic better, our hospital now have designed exclusive areas for cancer patients, the treatment room and nearby are thoroughly disinfected twice a day. At the same times, all inpatients will take nucleic acid testing for COVID-19 regularly. In our study, level of education, employment status, mode of transport, and SSRS score were independent predictive factors for PICCs care delay. Patients who received anti-tumor treatment, and patients experiencing financial strain tended to have higher SSRS scores. We also found that living with family could decrease the risk of depression. We have made some suggestions as solutions to improve the current situation. Official departments should strive to heighten public awareness of prevention and intervention strategies, and disseminate daily updates regarding infectious cases online and through social media $(42,43)$. Cancer care providers should follow standard precautions such as hand and respiratory hygiene, safe waste management, and equipment disinfection to prevent the spread of COVID-19. The patients should learn to protected themselves from this pandemic, overcome the fear for COVID-19 and try their best to receive nursing and treatment on time at the same times. Meanwhile, families, companies, and society are encouraged to offer increased financial respite, emotional support, greater appointment flexibility, and transportation support to optimize the care of patients during this COVID-19 pandemic.

In conclusion, the COVID-19 pandemic represents a tremendous cancer care challenge for our oncology community. In this study of PICCs care delay, we identified that physical aspects, social factors, and psychological status were the most important factors affecting the health care seeking behaviors. Increased efforts should be made by families and the broader society to ensure the best care for cancer patients is potentiated.

\section{Acknowledgments}

Funding: None.

\section{Footnote}

Reporting Checklist: The authors have completed the STROBE reporting checklist. Available at http://dx.doi. org/10.21037/apm-20-1887

Data Sharing Statement: Available at http://dx.doi. org/10.21037/apm-20-1887

Conflicts of Interest: All authors have completed the ICMJE uniform disclosure form (available at http://dx.doi. org/10.21037/apm-20-1887). The authors have no conflicts of interest to declare.

Ethical Statement: The authors are accountable for all aspects of the work in ensuring that questions related to the accuracy or integrity of any part of the work are appropriately investigated and resolved. Our study was approved by the Institutional Review Board of the Fifth 
Affiliated Hospital of Sun Yat-sen University (Approval No. ChiCTR2000029830). The study was conducted in accordance with the Declaration of Helsinki (as revised in 2013). All participants were fully informed and gave consent before taking questionnaires.

Open Access Statement: This is an Open Access article distributed in accordance with the Creative Commons Attribution-NonCommercial-NoDerivs 4.0 International License (CC BY-NC-ND 4.0), which permits the noncommercial replication and distribution of the article with the strict proviso that no changes or edits are made and the original work is properly cited (including links to both the formal publication through the relevant DOI and the license). See: https://creativecommons.org/licenses/by-nc-nd/4.0/.

\section{References}

1. Etkind SN, Bone AE, Lovell N, et al. The Role and Response of Palliative Care and Hospice Services in Epidemics and Pandemics: A Rapid Review to Inform Practice During the COVID-19 Pandemic. J Pain Symptom Manage 2020;60:e31-e40.

2. Kannan S, Shaik Syed Ali P, Sheeza A, et al. COVID-19 (Novel Coronavirus 2019) - recent trends. Eur Rev Med Pharmacol Sci 2020;24:2006-11.

3. Li LQ, Huang T, Wang YQ, et al. COVID-19 patients' clinical characteristics, discharge rate, and fatality rate of meta-analysis. J Med Virol 2020;92:577-83.

4. Singhal T. A Review of Coronavirus Disease-2019 (COVID-19). Indian J Pediatr 2020;87:281-6.

5. Boettler T, Newsome PN, Mondelli MU, et al. Care of patients with liver disease during the COVID-19 pandemic: EASL-ESCMID position paper. JHEP Rep 2020;2:100113.

6. Guo YR, Cao QD, Hong ZS, et al. The origin, transmission and clinical therapies on coronavirus disease 2019 (COVID-19) outbreak - an update on the status. Mil Med Res 2020;7:11.

7. Zhang WR, Wang K, Yin L, et al. Mental Health and Psychosocial Problems of Medical Health Workers during the COVID-19 Epidemic in China. Psychother Psychosom 2020;89:242-50.

8. Shankar A, Saini D, Roy S, et al. Cancer Care Delivery Challenges Amidst Coronavirus Disease - 19 (COVID-19) Outbreak: Specific Precautions for Cancer Patients and Cancer Care Providers to Prevent Spread. Asian Pac J Cancer Prev 2020;21:569-73.
9. Greenberg N, Docherty M, Gnanapragasam S, et al. Managing mental health challenges faced by healthcare workers during covid-19 pandemic. BMJ 2020;368:m1211.

10. De Felice F, Polimeni A, Valentini V. The impact of Coronavirus (COVID-19) on head and neck cancer patients' care. Radiother Oncol 2020;147:84-5.

11. Vahia IV, Blazer DG, Smith GS, et al. COVID-19, Mental Health and Aging: A Need for New Knowledge to Bridge Science and Service. Am J Geriatr Psychiatry 2020;28:695-7.

12. Wei $W$, Jiang $H$, Chen $W$, et al. How should we implement radiotherapy for cancer patients in China during the endemic period of COVID-19? Radiother Oncol 2020;147:100-2.

13. Bitar N, Kattan J, Kourie HR, et al. The Lebanese Society of Medical Oncology (LSMO) statement on the care of patients with cancer during the COVID-19 pandemic. Future Oncol 2020;16:615-7.

14. Salako O, Okunade K, Allsop M, et al. Upheaval in cancer care during the COVID-19 outbreak. Ecancermedicalscience 2020;14:ed97.

15. Wang H, Zhang L. Risk of COVID-19 for patients with cancer. Lancet Oncol 2020;21:e181.

16. Kuderer NM, Choueiri TK, Shah DP, et al. Clinical impact of COVID-19 on patients with cancer (CCC19): a cohort study. Lancet 2020;395:1907-18.

17. Fiorillo A, Gorwood P. The consequences of the COVID-19 pandemic on mental health and implications for clinical practice. Eur Psychiatry 2020;63:e32.

18. Calabrò L, Peters S, Soria JC, et al. Challenges in lung cancer therapy during the COVID-19 pandemic. Lancet Respir Med 2020;8:542-44.

19. Scoppettuolo G, Biasucci DG, Pittiruti M. Vascular access in COVID-19 patients: Smart decisions for maximal safety. J Vasc Access 2020;21:408-10.

20. Song L, Li H. Malposition of peripherally inserted central catheter: Experience from 3,012 patients with cancer. Exp Ther Med 2013;6:891-3.

21. Duwadi S, Zhao Q, Budal BS. Peripherally inserted central catheters in critically ill patients - complications and its prevention: A review. Int J Nurs Sci 2018;6:99-105.

22. Zhou J, Li M, Tang Z. Peripherally inserted central catheter: how safe is it for acute myeloid leukemia patients? Med Princ Pract 2014;23:586.

23. Kwon S, Son SM, Lee SH, et al. Outcomes of bedside peripherally inserted central catheter placement: a retrospective study at a single institution. Acute Crit Care 2020;35:31-7. 
24. Piorkowska M, Al-Raweshidy Z, Yeong K. Improving Peripherally Inserted Central Catheter (PICC) care on a Trauma and Orthopaedics ward. BMJ Qual Improv Rep 2013;2:u464.w354.

25. Mukhtar S. Mental health and emotional impact of COVID-19: Applying Health Belief Model for medical staff to general public of Pakistan. Brain Behav Immun 2020;87:28-9.

26. Shaw SCK. Hopelessness, helplessness and resilience: The importance of safeguarding our trainees' mental wellbeing during the COVID-19 pandemic. Nurse Educ Pract 2020;44:102780.

27. Torales J, O'Higgins M, Castaldelli-Maia JM, et al. The outbreak of COVID-19 coronavirus and its impact on global mental health. Int J Soc Psychiatry 2020;66:317-20.

28. Bo HX, Li W, Yang Y, et al. Posttraumatic stress symptoms and attitude toward crisis mental health services among clinically stable patients with COVID-19 in China. Psychol Med 2020;27:1-2.

29. Ali A. Delay in OnabotulinumtoxinA Treatment During the COVID-19 Pandemic-Perspectives from a Virus Hotspot. Headache 2020;60:1183-6.

30. Williams VM, Kahn JM, Harkenrider MM, et al. COVID-19 impact on timing of brachytherapy treatment and strategies for risk mitigation. Brachytherapy 2020;19:401-11.

31. Wallis CJD, Novara G, Marandino L, et al. Risks from Deferring Treatment for Genitourinary Cancers: A Collaborative Review to Aid Triage and Management During the COVID-19 Pandemic. Eur Urol 2020;78:29-42.

32. Lee JH, Kim MU, Kim ET, et al. Prevalence and predictors of peripherally inserted central venous catheter associated bloodstream infections in cancer patients. Medicine (Baltimore) 2020;99:e19056.

33. Cotogni P. Focus on peripherally inserted central catheters in critically ill patients. World J Crit Care Med 2014;3:80-94.

34. Harrod M, Montoya A, Mody L, et al. Challenges for Nurses Caring for Individuals with Peripherally Inserted Central Catheters in Skilled Nursing Facilities. J Am Geriatr Soc 2016;64:2059-64.

35. Gao Y, Liu Y, Ma X, et al. The incidence and risk factors of peripherally inserted central catheter-related infection among cancer patients. Ther Clin Risk Manag 2015;11:863-71.

36. Shuja KH, Aqeel M, Jaffar A, et al. COVID-19 Pandemic and Impending Global Mental Health Implications. Psychiatr Danub 2020;32:32-5.

37. Song Y, Liu S, Lou T, et al. Risk factors associated with peripherally inserted central catheter-related venous thrombosis in hospitalized patients of advanced age. J Int Med Res 2020;48:300060518820744.

38. Badheka A, Bloxham J, Schmitz A, et al. Outcomes associated with peripherally inserted central catheters in hospitalised children: a retrospective 7-year single-centre experience. BMJ Open 2019;9:e026031.

39. Bareket-Bojmel L, Shahar G, Margalit M. COVID-19related economic anxiety is as high as health anxiety: findings from the USA, the UK, and Israel. Int J Cogn Ther 2020:1-09.

40. Rajkumar RP. COVID-19 and mental health: A review of the existing literature. Asian J Psychiatr 2020;52:102066.

41. Ahmed MZ, Ahmed O, Aibao Z, et al. Epidemic of COVID-19 in China and associated Psychological Problems. Asian J Psychiatr 2020;51:102092.

42. Gao J, Zheng P, Jia Y, et al. Mental health problems and social media exposure during COVID-19 outbreak. PLoS One 2020;15:e0231924.

43. Hua J, Shaw R. Corona Virus (COVID-19) "Infodemic" and Emerging Issues through a Data Lens: The Case of China. Int J Environ Res Public Health 2020;17:2309.
Cite this article as: $\mathrm{Hu} \mathrm{L}$, Tao $\mathrm{H}, \mathrm{Xu} \mathrm{X}$, Chen $\mathrm{H}$, Chang $\mathrm{K}$, Pei X, Hao F, He L, Chen Y, Liang Z, Luo T, Lin Z, Lv W, Long F. Factors for peripherally inserted central catheters care delay in cancer patients during the COVID-19 pandemic. Ann Palliat Med 2020;9(6):3818-3829. doi: 10.21037/apm-20-1887 